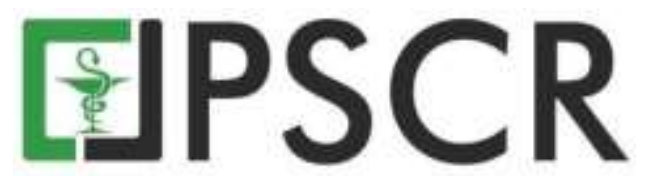

\title{
Evaluasi Terapi Antihipertensi Pada Pasien Preeklampsia Berat di Instalasi Rawat Inap RSUD Dr. Moewardi Periode Januari - Juni Tahun 2017
}

\author{
Wisnu Kundarto*dan Riskafiya Ni’matul Faizah \\ Program Studi D3 Farmasi, Sekolah Vokasi, Universitas Sebelas Maret, Jl. Kolonel Sutarto No. 150K, Surakarta, \\ Jawa Tengah, Indonesia, 57126 \\ *email korespondensi : wisnukundarto@staff.uns.ac.id \\ Received 29 January 2020, Accepted 7 May 2021, Published 15 July 2021
}

\begin{abstract}
Abstrak: Preeklampsia merupakan salah satu penyebab utama kematian ibu di Indonesia. Preeklampsia berat adalah sindrom klinis pada masa kehamilan (setelah kehamilan 20 minggu) yang ditandai dengan peningkatan tekanan darah $(\geq 160 / 110 \mathrm{mmHg})$ dan proteinuria. Penelitian ini bertujuan untuk mengevaluasi efektivitas penggunaan obat antihipertensi pada pasien preeklampsia berat di instalasi rawat inap RSUD Dr. Moewardi periode Januari - Juni 2017 dilihat dari ketepatan obat, dosis, dan target tekanan darah dibandingkan dengan guideline The American College of Obstetricians and Gynecologists (ACOG) tahun 2013. Penelitian ini merupakan penelitian deskriptif non eksperimental. Pengambilan data dilakukan secara retrospektif dengan teknik consecutive sampling dengan mencatat rekam medis yang memenuhi kriteria. Efektivitas penggunaan obat antihipertensi dinilai dengan melihat ketepatan obat, dosis, dan target tekanan darah berdasarkan ACOG tahun 2013. Terdapat 76 rekam medis yang memenuhi kriteria. Karakteristik pasien didominasi berusia 20-35 tahun (73,7\%), multigravida $(73,7 \%)$, serta usia kehamilan pada trimester III (96,1\%). Hasil evaluasi menunjukkan penggunaan obat antihipertensi yang diberikan adalah nifedipin $(65,79 \%)$, metildopa $(23,68 \%)$, dan kombinasi keduanya $(10,53 \%)$. Kesimpulan penelitian ini adalah penggunaan obat antihipertensi sudah efektif ditinjau dari tepat obat, tepat dosis, dan sesuai target tekanan darah berdasarkan ACOG tahun 2013.
\end{abstract}

Kata kunci: preeklampsia berat; tepat obat; tepat dosis

Abstract: The evaluation of antihypertension therapy in patients with severe preeclampsia at inpatient unit moewardi general hospital during january - june 2017 period. Preeclampsia is one of the main cause of maternal mortality in Indonesia. Severe preeclampsia is a clinical syndrome during pregnancy (after 20 weeks' gestation) characterized by elevated blood pressure $(\geq 160 / 110 \mathrm{mmHg}$ ) and proteinuria. The aim of this study was to evaluate the effectiveness of antihypertension drugs in patient with severe preeclampsia at inpatient unit Moewardi General Hospital duringJanuary - June 2017 period based on drug, dosage, and blood pressure target compared with the The American College of Obstetricians and Gynecologists (ACOG) 2013 guideline. This research was a descriptive non-experimental design. Data from medical record sampleswere collected retrospectively with consecutive sampling. Assessment of antihypertension drugs efectivity based on drug, dosage and blood pressure target appropriateness compared with ACOG 2013.Only 76 medical records were meet the criteria. Mostly subject were dominated by age 20 - 35 years $(73,7 \%)$, multigravida $(73,7 \%)$, and pregnancy at third semester $(96,1 \%)$. The result showed that antihypertension drugs were nifedipine $(65,79 \%)$, methyl dopa $(23,68 \%)$, and combination of them $(10,53 \%)$. The conclusion were all antihypertension drugs were effective based on drug, dosage and blood pressure target appropriateness compared with ACOG 2013 guidelines

Keywords: severe preeclampsia; drug appropriateness; dosage appropriateness 


\section{Pendahuluan}

Kematian ibu di Indonesia didominasi oleh tiga penyebab utama kematian yaitu perdarahan, hipertensi dalam kehamilan dan infeksi. Hipertensi pada kehamilan seperti hipertensi gestasional maupun preeklampsia terjadi pada 10 persen kehamilan serta menjadi penyebab utama kejadian morbiditas dan mortalitas ibu dan janin (Sonnaville et al., 2020). Data Profil Kesehatan Indonesia pada tahun 2019 memperlihatkan sebanyak 1280 kasus perdarahan, 1066 kasus hipertensi dalam kehamilan, dan 207 kasus infeksi menjadi penyebab kematian ibu (Kemenkes, 2020).

Penelitian terakhir tentang evaluasi obat antihipertensi pada pasien preeklamsia berat sudah pernah dilakukan di Indonesia, dengan hasil bervariasi. Penelitian Qoyimah (2016) di Rumah Sakit PKU Muhammadiyah Bantul menunjukkan bahwa antihipertensi yang digunakan pada total 17 pasien hanya nifedipin. Evaluasi penggunaan antihipertensi pada penelitian tersebut menunjukkan penggunaan nifedipin sudah tepat indikasi, tepat pasien, tepat obat, dan tepat dosis dibandingkan dengan JNC VII (2003). Penelitian Amri \& Mutmainah (2015) melaporkan dari total 76 pasien preeklampsia berat di RSUD Dr Moewardi Surakarta, sebanyak $49,19 \%$ tepat indikasi, ketepatan obat sebanyak $81,35 \%$, ketepatan dosis sebanyak $86,44 \%$, dan ketepatan pasien sebanyak 93,22\%. Penelitian ini menggunakan pembanding Panduan Nasional dan Pelayanan Kesehatan Preeklampsia (PNPK) tahun 2016 yang dikeluarkan oleh Perkumpulan Obstetri dan Ginekologi Indonesia. Hadad et al., (2019) melaporkan pemilihan obat pada pasien preeklampsia berat di Instalasi Rawat Inap RSUD dr. Soedarso Pontianak tahun 2018 yaitu sebesar 40,32\% penggunaan kombinasi nifedipin + metildopa, diikuti oleh nifedipintunggal $(14,52 \%)$, kombinasi nifedipin + metildopa + furosemid $(9,68 \%)$ serta metildopa tunggal $(8,06 \%)$ dari total 62 pasien. Penelitian tersebut juga menemukan ketidaktepatan pemilihan obat sebesar $11,29 \%$. Penelitian tersebut menggunakan pembanding Panduan Nasional dan Pelayanan Kedokteran Preeklampsia tahun 2016 dan Queensland Clinical Guideline tahun 2015.

Penelitian Amri \& Mutmainah (2015) menunjukkan masih ditemukannya ketidaktepatan obat dan dosis. Pemilihan obat - obatan selama kehamilan harus mempertimbangkan antara rasio manfaat yang lebih besar daripada risiko bagi ibu maupun janin untuk menghasilkan terapi yang aman dan rasional. Pemberian terapi antihipertensi yang tidak tepat dapat saja menyebabkan risiko hipotensi ataupun potensi efek samping pada janin (Odigboegwu et al., 2018). Hal inilah yang melatar belakangi pentingnya penelitian evaluasi efektivitas penggunaan obat antihipertensi pada pasien preeklampsia berat di instalasi rawat inap RSUD Dr. Moewardi periode Januari - Juni 2017 ini dilakukan. Efektivitas penggunaan obat dilihat dari ketepatan obat, dosis, dan target tekanan darah yang dicapai yaitu $<160 / 100 \mathrm{mmHg}$. Ketepatan obat dan 
dosis dibandingkan dengan guideline The American College of Obstetricians and Gynecologists (ACOG) tahun2013. JNC VII (2003) hanya menyebutkan obat-obat hipertensi yang aman untuk janin, namun belum memuat target tekanan darah pasien hipertensi dengan kehamilan. ACOG tahun 2013 dan PNPK tahun 2016 menyatakan target penurunan tekanan darah pasien preeklampsia berat tekanan darah sistolik sebesar $<160 \mathrm{mmHg}$ dan diastolik sebesar $<110 \mathrm{mmHg}$. Peneliti menggunakan guideline ACOG ini dikarenakan penelitian Amri \& Mutmainah (2015) telah menggunakan PNPK tahun 2016. Secara umum obat-obat antihipertensi yang digunakan dan target tekanan darah kedua guideline tersebut sama.

\section{Bahan dan Metode}

Penelitian ini telah mendapatkan izin kelaikan etik dengan nomor 1.212/XII/HREC/2017 dari Komisi Etik RSUD Dr. Moewardi. Penelitian ini merupakan penelitian non eksperimental dengan pendekatan deskriptif dan pengumpulan data secara retrospektif dengan menggunakan data rekam medik. Alat yang diperlukan pada penelitian ini adalah lembar pengumpul data, serta guideline The American College of Obstetricians and Gynecologists (ACOG) tahun 2013. Peneliti menggunakan guideline ACOG tahun 2013 meskipun PNPK tahun 2016 umum digunakan pada penelitian di Indonesia. Terkait obat-obat antihipertensi pasien preeklampsia berat dan target tekanan darah, guideline ACOG tahun 2013 dan PNPK tahun 2016 memiliki makna yang sama. Bahan yang diperlukan berupa catatan rekam medis pasien preeklampsia berat yang dirawat di instalasi rawat inap RSUD Dr. Moewardi Periode Januari-Juni Tahun 2017.

Populasi yang digunakan dalam penelitian ini adalah semua pasien preeklampsia berat di instalasi rawat inap RSUD Dr. Moewardi periode Januari - Juni Tahun2017. Sampel diambil dengan teknik purposive sampling. Kriteria inklusi pada penelitian ini adalah pasien mempunyai tekanan darah sebelum terapi yaitu $\geq 160 / 100 \mathrm{mmHg}$, usia kehamilan $\geq 20$ minggu, mengalami proteinuria dengan hasil dipstik > +1 atau > $300 \mathrm{mg} / 24$ jam, mendapatkan terapi obat antihipertensi, mempunyai data rekam medis lengkap meliputi usia pasien, usia kandungan, status gravida, obat dan dosis antihipertensi, serta tekanan darah sebelum dan sesudah terapi.

Data yang diperoleh selanjutnya dianalisis secara deskriptif dan disajikan dalam bentuk table untuk melihat karakteristik pasien preeklampsia berat dan evaluasi efektivitas penggunaan obat antihipertensi. Karakteristik pasien pada penelitian ini meliputi usia pasien, usia kandungan, dan status gravida. Evaluasi efektivitas penggunaan obat antihipertensi meliputi data ketepata nobat, dosis dan target tekanan darah pasien. Pengobatan antihipertensi dikatakan efektif jika tepat obat, tepat dosis, dan target outcome tekanan darah pasien $<160 / 100 \mathrm{mmHg}$ saat pasien diperbolehkan keluar rumah sakit. 


\section{Hasil dan Pembahasan}

Populasi pada penelitian ini berjumlah 101 pasien dan yang memenuhi kriteria hanya diperoleh 76 pasien preeklampsia berat dengan jumlah frekuensi pemberian obat antihipertensi sebanyak 153 kasus. Pasien yang di eksklusi yaitu sebanyak 28 pasien tidak memiliki catatan rekam medis yang lengkap, dan 7 pasien tidak mendapatkan pengobatan antihipertensi.

\subsection{Karakteristik pasien}

3.1.1 Distribusi pasien berdasarkan usia.

Usia ibu hamil merupakan salah satu faktor yang mempengaruhi terjadinya kejadian preeklampsia berat. Ibu hamil dengan usia > 35 tahun beresiko terjadi preeklampsia karena terjadi perubahan akibat faktor penuaan. Ibu hamil usia $<20$ tahun rahim belum siap dalam menghadapi kehamilan, dan secara psikologis mental belum siap sehingga mengakibatkan hipertensi (Kurniasari \& Arifandini, 2015).

Pembagian usia pasien pada penelitian ini berdasarkan dengan usia resiko melahirkan yaitu $<20$ tahun dan $>35$ tahun serta usia aman untuk melahirkan yaitu 20-35 tahun (Septiasih, 2018). Distribusi pasien berdasarkan usia dapat dilihat pada Tabel 1.

Tabel 1. Distribusi berdasarkan usia pasien preeklampsia berat $(\mathrm{N}$ total $=76)$. Persentase $=$ jumlah pasien tiap setiap kelompok / jumlah seluruh pasien x $100 \%$.

\begin{tabular}{ccc}
\hline Usia (Tahun) & Jumlah Pasien & Persentase (\%) \\
\hline$<20$ & 1 & 1,3 \\
$20-35$ & 56 & 73,7 \\
$>35$ & 19 & 25,0 \\
Total & 76 & 100 \\
\hline
\end{tabular}

Pasien dengan kelompok usia 20-35 tahun memiliki persentase paling tinggi yaitu sebesar $73,7 \%$ sebanyak 56 pasien (Tabel 1). Usia berkaitan dengan peningkatan dan penurunan fungsi tubuh. Usia kehamilan yang baik berada pada rentang 20-35 tahun (Nursal et al., 2015). Penelitian Qoyimah tahun 2016 menunjukkan hasil pasien preeklampsia berat sering ditemui dalam rentang umur 20-35 tahun yaitu 70,6\% dari 17 kasus (Qoyimah, 2016). Usia seringkali dikaitkan dengan risiko terjadinya hipertensi, penelitian Nurmainah \& Alfan (2021) menunjukan bahwa perbedaan usai berhubungan dengan perbedaan tekanan darah. Hasil tersebut bias saja terjadi diduga karena banyak faktor lain yang dapat berpengaruh seperti pekerjaan. Pekerjaan dikaitkan dengan aktifitas fisik dan stress. Stres dapat memicu tubuh untuk memproduksi hormon kortisol. Kortisol berefek dapat meningkatkan curah jantung dan tekanan darah (Grum et al., 2017). Namun pada penelitian ini, data rekam medis seluruh pasien tidak mencantumkan jenis pekerjaan sehingga peneliti tidak dapat mengetahui jenis pekerjaan pasien. 
3.1.2 Distribusi pasien berdasarkan status gravida.

Status gravida/kehamilan juga termasuk faktor resiko yang dapat menyebabkan terjadinya preeklampsia berat. Distribusi pasien preeklampsia berat di instalasi rawat inap RSUD Dr. Moewardi berdasarkan status gravida dapat dilihat pada Tabel 2.

Tabel 2. Distribusi berdasarkan status gravida $(\mathrm{N}$ total $=76)$. Persentase $=$ jumlah jumlah pasien tiap setiap kelompok/jumlah seluruh pasien x $100 \%$.

\begin{tabular}{ccc}
\hline Status Gravida & Jumlah Pasien & Persentase (\%) \\
\hline Primigravida & 20 & 26,3 \\
Multigravida & 56 & 73,7 \\
Total & 76 & 100 \\
\hline
\end{tabular}

Persentase tertinggi yaitu pada kelompok multigravida (status kehamilan ibu >1 kali) sebanyak 73,7 \% (Tabel 2). Hasil tersebut berbeda dengan penelitian Qoyimah tahun 2016 di RS PKU Muhammadiyah Bantul yang menunjukkan bahwa kelompok primigravida memiliki persentase tertinggi terjadinya preeklampsia berat yaitu sebesar 52,9\% dari 17 pasien. Kejadian preeklampsia berat lebih sering terjadi pada kehamilan pertama. Primigravida rentan mengalami stres sehingga dapat memicu tubuh untuk memproduksi hormon kortisol. Kortisol berefek dapat meningkatkan curah jantung dan tekanan darah (Grum et al., 2017). Respon imun juga dapat menjadi penyebab kejadian preeklampsia pada primigravida akibat reaksi fetoplasenta dengan jaringan ibu (Tessema et al., 2015).

Hasil penelitian ini status gravida yang lebih banyak mengalami preeklampsia berat adalah kelompok multigravida. Hal tersebut diduga dapat saja terjadi jika faktor lain seperti riwayat hipertensi pasien dan riwayat adanya penyakit preeklampsia berat pada keluarga pasien sehingga jumlah pasien kelompok tersebut memiliki persentase yang lebih besar dibandingkan kelompok primigravida.

Faktor riwayat hipertensi pasien sebelum kehamilan dan riwayat preeklampsia berat pada keluarga pasien berpengaruh dengan tingkat kejadian preeklampsia berat. Hal ini karena seorang ibu yang mempunyai riwayat hipertensi berisiko lebih besar mengalami preeklampsia (Cunningham et al., 2013). Selain itu riwayat keluarga yang pernah mengalami preeklampsia akan meningkatkan resiko sebesar 2,6 kali lipat (Grum et al., 2017). Namun kedua faktor ini tidak dapat diketahui secara pasti oleh peneliti karena dalam data rekam medis pasien tersebut tidak dicantumkan.

\subsubsection{Distribusi pasien berdasarkan usia kehamilan.}

Kejadian preeklampsia sering terjadi pada usia kehamilan diatas 20 minggu karena perubahan plasenta normal. Hal ini sesuai dengan teori iskemia implantasi plasenta bahwa kejadian preeklampsia semakin meningkat seiring tuanya kehamilan tepatnya diatas usia kehamilan 20 minggu. Terapi definitif pada preeklampsia adalah dengan melahirkan bayi 
(Sidani \& Siddik-Sayyid, 2011). Melahirkan bayi dapat mengurangi resiko memburuknya penyakit maupun terjadinya komplikasi (Osungbade \& Ige, 2011). Distribusi pasien berdasarkan usia kehamilan dapat dilihat pada Tabel 3.

Tabel 3. Distribusi berdasarkan usia kehamilan $(\mathrm{N}$ total=76). Persentase $=$ jumlah pasien tiap setiap kelompok / jumlah seluruh pasien x $100 \%$.

\begin{tabular}{ccc}
\hline Usia Kehamilan & Jumlah Pasien & Persentase (\%) \\
\hline Trimester I & - & - \\
Trimester II & 3 & 3,9 \\
Trimester III & 73 & 96,1 \\
Total & 76 & 100 \\
\hline
\end{tabular}

Trimester III merupakan persentase tertinggi subjek penelitian ini (Tabel 3) meskipun juga ada subjek menunjukkan preeklampsia pada trimester II. Hasil tersebut juga sesuai dengan penelitian Qoyimah tahun 2016 bahwa pada semua subjek penelitiannya $(\mathrm{N}=17)$ juga menunjukkan kelompok trimester III merupakan waktu paling banyak terjadi preeklampsia berat. Adanya subjek pada trimester II diduga mungkin karena adanya faktor lain yang tidak tercatat di rekam medis seperti riwayat keluarga.

\subsection{Evaluasi penggunaan obat antihipertensi}

\subsubsection{Data penggunaan obat antihipertensi.}

Guideline ACOG 2013 memberikan rekomendasi pemberian antihipertensi menurut yaitu labetalol, nifedipin, metildopa dan hydralazin. Adapun penggunaan obat antihipertensi pasien dapat dilihat pada Tabel 4 .

Tabel 4. Data penggunaan obat antihipertensi $(\mathrm{N}=76)$. Persentase $=$ jumlah frekuensi setiap obat / total frekuensi pemberian antihipertensi preeklampsia berat berat x $100 \%$.

\begin{tabular}{ccccc}
\hline Terapi & Nama Obat & Dosis & JumlahKasus & Persentase (\%) \\
\hline Tunggal & Nifedipin & $3 \times 10 \mathrm{mg}$ & 50 & 65,79 \\
& Metildopa & $3 \times 250 \mathrm{mg}$ & 18 & 23,68 \\
Kombinasi & Nifedipin + Metildopa & $3 \times 10 \mathrm{mg}$ & 8 & 10,53 \\
& & $3 \times 250 \mathrm{mg}$ & & 100 \\
\hline
\end{tabular}

Nifedipin memiliki persentase tertinggi (Tabel 4) pada penelitian ini. Hasil ini juga sesuai dengan penelitian Qoyimah (2016) bahwa nifedipin merupakan obat antihipertensi yang paling sering diberikan bagi pasien preeklampsia. Alasan nifedipin banyak digunakan dapat dilihat pada pembahasan ketepatan obat. Sebanyak 8 pasien mendapatkan terapi kombinasi. Menurut JNC VII (2003), terapi hipertensi dapat digunakan kombinasi jika tekanan darah belum berhasil terkontrol dengan monoterapi.

- Evaluasi ketepatan obat.

Ketepatan obat dilihat dari pemilihan antihipertensi yang disesuaikan dengan guideline ACOG tahun 2013, dilihat sesuai tidaknya merupakan drug of choice dari antihipertensi yang 
diberikan pada pasien preeklampsia berat. Ketepatan obat berkaitan dengan pemilihan kelas terapi dan jenis obat berdasarkan pertimbangan manfaat, keamanan dan mutu obat. Seperti terlihat pada Tabel 4 sebelumnya, maka penggunaan nifedipin, metildopa, dan kombinasi keduanya sudah tepat obat. Kedua jenis obat antihipertensi tersebut merupakan drug of choice untuk pasien preeklampsia berat menurut guideline ACOG 2013 selain labetalol dan hidralazin. Metildopa menstimulasi reseptor alfa adrenergik sehingga akan mengurangi efek simpatik nor efinefrin pada jantung, ginjal, dan pembuluh darah perifer. Hal ini akan mengurangi tekanan darah. Metildopa telah digunakan secara luas pada pasien preeklampsia. Penggunaan metildopa dapat saja kurang berefek pada sebagian pasien dikarenakan onset metildopa hanya 3-6 jam sehingga dapat dikombinasikan dengan obat antihipertensi lain.

Nifedipin adalah obat penghambat kanal kalsium yang juga telah lama digunakan pada pasien hipertensi dalam kondisi hamil. Adanya penghambatan kanal kalsium akan berefek ke penurunan denyut jantung dan akhirnya dapat mengurangi tekanan darah (Odigboegwu et al., 2018). Nifedipin merupakan obat yang ideal untuk penanganan preeklampsia karena nifedipin mempunyai onset yang cepat, dapat diberikan peroral dan efektif menurunkan tekanan darah tanpa menyebabkan efek samping yang berbahaya. Selain itu, nifedipin juga memberikan aksi tanpa menurunkan aliran darah uteroplasenta dan tidak menyebabkan abnormalitas pada jantung janin (Qoyimah, 2016).

Studi randomized controlled trial yang dilakukan oleh Easterling et al. (2019) membandingkan efikasi tiga obat oral antihipertensi yaitu labetalol, nifedipin, dan metildopa pada kehamilan disertai tekanan darah tinggi. Penelitian tersebut melibatkan 894 perempuan hamil dengan hipertensi, sebanyak 298 orang menggunakan nifedipin, 295 orang menggunakan labetalol, dan 301 orang menggunakan metildopa. Hasil penelitian menunjukkan semua obat mampu menurunkan tekanan darah pada sebagian besar subjek. Sebagai agen monoterapi, nifedipin menunjukkan efikasi yang lebih baik dari labetalol dan metildopa.

Tabel 5. Evaluasi ketepatan dosis penggunaan antihipertensi pasien $(\mathrm{N}=76)$. Persentase $=$ dihitung dari $\mathrm{n} / \mathrm{N} \times 100 \%$.

\begin{tabular}{|c|c|c|c|}
\hline $\begin{array}{l}\text { Nama Obat } \\
\text { /jumlah (n) }\end{array}$ & $\begin{array}{c}\text { Dosis } \\
\text { pemakaian }\end{array}$ & Dosis menurut ACOG (2013) & $\begin{array}{l}\text { Persentase } \\
(\%)\end{array}$ \\
\hline $\begin{array}{l}\text { Nifedipin/ } 50 \\
\text { kasus }\end{array}$ & $3 \times 10 \mathrm{mg}$ & $\begin{array}{l}\text { 10-20 mg, jika perlu diulang setiap } 30 \text { menit } \\
\text { lalu } 10-20 \mathrm{mg} / 2-6 \text { jam }\end{array}$ & $\begin{array}{c}\text { Tepatdosis } \\
(65,79)\end{array}$ \\
\hline $\begin{array}{l}\text { Metildopa/18 } \\
\text { kasus }\end{array}$ & $\begin{array}{l}3 \times 250 \mathrm{mg} \\
3 \times 500 \mathrm{mg}\end{array}$ & $\begin{array}{l}0,5-3 \text { gram/hari terbagi dalam } 2 \text { hingga } 3 \\
\text { kali dosis }\end{array}$ & $\begin{array}{l}\text { Tepat dosis } \\
\quad(23,68)\end{array}$ \\
\hline $\begin{array}{l}\text { Nifedipin }+ \\
\text { Metildopa/8 } \\
\text { kasus }\end{array}$ & $\begin{array}{l}\text { Nifedipin: } 3 \\
\quad \text { x } 10 \mathrm{mg} \\
\text { Metildopa: } 3 \\
\text { x } 250 \mathrm{mg}\end{array}$ & $\begin{array}{l}\text { Nifedipin: } 10-20 \mathrm{mg} \text {, jika perlu diulang } \\
\text { setiap } 30 \text { menit kemudian } 10-20 \mathrm{mg} \text { setiap } \\
2-6 \text { jam } \\
\text { Metildopa: } 0,5-3 \text { gram/hari terbagi dalam } \\
2 \text { hingga } 3 \text { kali dosis }\end{array}$ & $\begin{array}{c}\text { Tepat dosis } \\
(10,53)\end{array}$ \\
\hline
\end{tabular}


- Evaluasi ketepatan dosis.

Tepat dosis adalah jumlah obat yang diberikan berada dalam rentang terapi menurut guideline ACOG 2013. Data ketepatan dosis obat antihipertensi tersebut dapat dilihat pada Tabel 5, dimana menunjukan bahwa semua obat antihipertensi yang diberikan pada pengobatan pasien sudah tepat dosis.

- Evaluasi outcome terapi berdasarkan target tekanan darah.

Hasil penelitian menunjukkan tekanan darah semua pasien saat keluar rumah sakit sudah mencapai target terapi yaitu < 160/100 mmHg. Berdasarkan guideline ACOG tahun 2013 target terapi yang ingin dicapai setelah pemberian obat antihipertensi adalah $<160 / 100 \mathrm{mmHg}$ pada saat pasien diperbolehkan pulang. Berdasarkan hasil ketepatan obat, dosis, dan pencapaian outcome target tekanan darah, maka semua obat antihipertensi pada penelitian ini telah efektif. Studi randomized controlled trial yang dilakukan oleh Easterling et al. (2019) juga menunjukkan bahwa penggunaan nifedipin mampu mencapai outcome target tekanan darah yang signifikan dibandingkan dengan kelompok yang menggunakan metildopa dan labetalol. Penelitian tersebut menentukan target tekanan darah sistolik sebesar 120-150 mmHg, dan tekanan darah diastolik sebesar 70-100 $\mathrm{mmHg}$.

Keterbatasan penelitian ini adalah peneliti tidak melihat hubungan antar faktor resiko kejadian preeklampsia berat. Penelitian ini juga hanya membahas terapi obat hipertensi saja, dan tidak membahas obat-obat lain yang digunakan. Data fungsi ginjal terkait kondisi proteinuria selama dan setelah pemberian antihipertensi juga tidak diamati. Peneliti juga hanya menggunakan guideline ACOG tahun 2013 saja sehingga hasil penelitian yang diperoleh ini kurang lengkap dan maksimal. Penelitian selanjutnya disarankan dapat bersifat prospektif, membahas mengenai korelasi antar faktor resiko, melihat manajemen terapi secara keseluruhan terutama kondisi proteinuria pasien dibandingkan dengan guideline yang lebih baru dan standar pengobatan di rumah sakit setempat. Sampel yang digunakan juga hendaknya bisa lebih banyak dan menggunakan rekam medis terbaru.

\section{Kesimpulan}

Obat antihipertensi yang digunakan dari 76 pasien preeklampsia berat di instalasi rawat inap RSUD Dr. Moewardi periode Januari sampai Juni 2017 yaitu nifedipin sebanyak 50 kasus $(65,79 \%)$, metildopa sebanyak 18 kasus $(23,68 \%)$, dan nifedipin dan metildopa sebanyak 8 kasus (10,53\%). Dibandingkan dengan guideline ACOG tahun 2013 didapatkan semua antihipertensi yang digunakan sudah efektif karena tepat obat, tepat dosis dan telah mencapai target outcome tekanan darah $<160 / 100 \mathrm{mmHg}$ saat pasien keluar rumah sakit.

\section{Deklarasi Konflik Kepentingan}

Semua penulis menyatakan bahwa tidak ada konflik kepentingan dalam penelitian ini. 


\section{DAFTAR PUSTAKA}

ACOG, (2013), Hypertension in Pregnancy, Washington DC: American College of Obstetricians and Gynecologists.

Amri, M.U., and Mutmainah, N, (2015), Studi Penggunaan Obat Antihipertensi Pada Pasien Preeklampsia Berat di Instalasi Rawat Inap Rumah Sakit Daerah Dr. Moewardi Surakarta Tahun 2014, Skripsi, tersedia dalam http://eprints.ums.ac.id/41245/, diakses 10 April 2021.

Cunningham, F.G., Leveno, K.J., Bloom, S.L., Hauth, J.C., Rouse, D.J., and Spong, C.Y., (2013), Williams Obstetrics, 23th Edition, 706-749, TheMcGraw-Hill Companies, New York.

Easterling, T., Mundle, S., Bracken, H., Parvekar, S., Mool, S., Magee, L.A., van Dadelszen, P., Shochet, T, and Winikoff, B., (2019), Oral Antihypertensive Regimens (Nifedipine retard, Labetalol, and Methyldopa) for Management of Severe Hypertension in Pregnancy: an Open Label, Randomized Controlled Trial, Lancet, 394: 1011-1021.

Grum, T., Seifu, A., Abay, M., Angesom, T., and Tsegay, L..(2017), Determinants of Preeclampsia/Eclampsia among Women Attending Delivery Services in Selected Public Hospitals of Addis Ababa, Ethiopia: a Case Control Study, BMC Pregnancy Childbirth 17(1): 307.

Hadad, F.M., Nurmainah, and Andrie, M., (2019), Evaluasi Ketepatan Pemilihan Antihipertensi Pada Pasien Preeklampsia Berat di Instalasi Rawat Inap RSUD Dr. Soedarso Pontianak, Jurnal Mahasiswa Farmasi Fakultas Kedokteran UNTAN, 4 (1): 1-12.

JNC VII Express, (2003), The Seventh Report of the Joint National Committee on Prevention, Detection, Evaluation, and Treatment of High Blood Pressure.

Kementerian Kesehatan Republik Indonesia, (2020), Profil Kesehatan Indonesia Tahun 2019, tersedia dalam https://pusdatin.kemkes.go.id/resources/download/pusdatin/profilkesehatan-indonesia/Profil-Kesehatan-indonesia-2019.pdf, diakses 8 Juli 2021.

Kurniasari, D., and Arifandini, F., (2015), Hubungan Usia, Paritas, dan Diabetes Mellitus pada Kehamilan dengan Kejadian Preeklampsia pada Ibu Hamil di Wilayah Kerja Puskesmas Rumbia Kabupaten Lampung Tengah tahun 2014, J Kesehatan Holistik , 9(3): 142-150.

Nurmainah and Alfan, N., (2021), Analisis Kesintasan Laju Kejadian Hipertensi Berdasarkan Perbedaan Usia Akseptor Kontrasepsi Oral, Journal of Pharmaceutical Science and Clinical Research, 2021, 6(01): 12-19.

Nursal, D.G.A., Tamela, P., dan Fitrayeni, (2015), Faktor Risiko Kejadian Preeklampsia pada Ibu Hamil di RSUP Dr. M. Djamil Padang Tahun 2014, Jurnal Kesehatan Masyarakat Andalas, 10 (1) : 38-44.

Odigboegwu, O., Pan, L.J., and Chatterjee, P., (2018), Use of Antihypertensive Drugs During Preeclampsia, Front Cardiovasc Med, 5:50.

Osungbade, K.O., and Ige, O.K., (2011), Public Health Perspectives of Preeclampsia in developing countries: implication for health system strengthening, Journal of Pregnancy, 10:1-6.

Perkumpulan Obstetri dan Ginekologi Indonesia, (2016), Pedoman Nasional Pelayanan Kedokteran: Diagnosis dan Tata Laksana Preeklampsia.

Qoyimah, U.N., (2016), Evaluasi Penggunaan Obat Antihipertensi Pada PasienPreeklampsia Berat Rawat Inap di RS PKU Muhammadiyah Bantul Periode Januari-Desember 2015, JurnalIlmiahIbnuSina I(2), 192-202, Yogyakarta : Universitas Ahmad Dahlan.

Septiasih, (2018), Faktor Risiko Kejadian Preeklampsia pada Ibu Bersalin di RSUD Wonosari Kabupaten Gunung Kidul Tahun 2017, Skripsi, tersedia dalam http://eprints.poltekkesjogja.ac.id diakses 10 April 2021.

Sidani, M and Siddik-Sayyid, S,M, (2011), Preeclampsia, A New Perspective in 2011,MEJA, 21 (2), 207-216.

Sonnaville, C.M.W., Hukkelhoven, C.W., Vlemmix, F., Groen, H, Schutte, J.M., Mol, B.W., and Pampus, M.G.V., (2020), Impact of Hypertension and Preeclampsia Intervention 
Trial at Near Term-I (HYPITAT-1) on Obstetric Management and Outcome in The Netherlands, Ultrasound Obstet Gynecol , 55 : 58-67.

Tessema, G.A., Tekeste, A., and Ayele, T.A. (2015), Preeclampsia and Associated Factors Among Pregnant Women Attending Antenatal Care in Dessie Referral Hospital, Northeast Ethiopia: a Hospital-Based Study, BMC Pregnancy ChildBirth 15(1): 1-7.

\section{(c) (1) ()}

(C) 2021 by the authors. Submitted for possible open access publication under the terms and conditions of the Creative Commons Attribution-ShareAlike 4.0 International (CC BY-SA 4.0) license (https://creativecommons.org/licenses/by-sa/4.0/). 